\title{
Identification of Synonymous Codon Usage Bias in the Pseudorabies Virus UL31 Gene
}

\author{
Mingsheng Cai ${ }^{1,2}$, Zhiyao Zhao ${ }^{1}$, Junyi Zhu ${ }^{1}$, Jianhong Chen ${ }^{2}$, Bingyun Wang ${ }^{2}$, Zi Li ${ }^{1}$, Meili \\ $\mathrm{Li}^{1{ }^{*}}$ \\ ${ }^{1}$ Department of Pathogenic Biology and Immunology, Guangzhou Medical University, Guangzhou, China \\ 2 Department of Veterinary Medicine, Foshan Science and Technology University, Foshan, China \\ *Corresponding author: Meili Li, Department of Pathogenic Biology and Immunology, Guangzhou Medical University, 195 Dongfeng Xi Road, Yuexiu, Guangzhou 510182, Guangdong, \\ P.R. China. Tel: + 1186-2081340200, Fax: + 1186-2081340200, E-mail: meili_2011@hotmail.com
}

Received: July 25, 2013; Revised: August 30, 2013; Accepted: September 03, 2013

\begin{abstract}
Background: Little knowledge of synonymous codon usage pattern of pseudorabies virus (PRV) genome, especially the UL31 gene in the process for its evolution is available.

Objectives: In the present study, the codon usage bias between PRVUL31 sequence and the UL31-like sequences was identified.

Materials and Methods: We used a comprehensive analysis on codon usage pattern in the PRV UL31 gene and the UL31-like genes of 48 reference herpesviruses by calculating codon adaptation index, ENC, RSCU and EMBOSS assays.

Results: Cluster analysis demonstrated that the codon usage bias of UL31-like genes of 49 herpesviruses had a very close relation to their gene functions. In addition, comparison of codon preferences in the UL31 gene of PRV with those of E. coli, yeast and human showed that there were 33 codons showing discrete usage differences between $P R V$ and yeast, 24 between $P R V$ and $E$. coli, but 22 between $P R V$ and human. Although there were slightly fewer differences in codon usages between PRV and human, the difference is unlikely to be statistically significant, and experimental studies are necessary to establish the most suitable expression system for PRVUL31.

Conclusions: These results may further our comprehending of the evolution, pathogenesis and functional studies of PRV.
\end{abstract}

Keywords: Alpha herpesvirus; Codon Usage Bias; Pseudorabies Virus; UL31 gene

\section{Background}

Within the ordinary genetic codes exploited in a large amount of varied ways, all amino acids (aa) are coded by two to six synonymous codons, except Met and Trp. However, degenerate codons are not employed at identical frequencies within organism. A phenomenon designated codon usage bias (1-3). Codon usage bias among synonymous codons has been documented for numerous genes in variant species (3-9). It is reported that synonymous codon usage bias may be connected with different biological factors $(6,10-13)$. Further analysis found that synonymous codon usage pattern changed at distinct sites along a coding sequence (14), balances of strong versus weak base pair bonding $(15,16)$, maintenance of DNA and RNA secondary structure (17), and translational efficiency and fidelity (6). Aujeszky's disease, which is provoked by the pathogenic factor of Pseudorabies virus (PRV) (also known as Suid herpesvirus 1, SuHV-1), is a regularly lethal disease with a global distribution that influences swine, mainly and other domestic and wild animals incidentally (18-22). PRV belongs to the genus Varicellovirus, subfamily alpha herpesvirinae, which is a swine alpha herpesvirus $(20$, 23-26)

\section{Objectives}

PRV UL31 gene, an 816-base pair sequence encodes a putative polypeptide of 271 aa residues named UL31 protein. Regarding the role of UL31 gene product played in the herpesvirus life cycle, herpes simplex virus 1 (HSV-1) UL31 (27-36) and Epstein-Barr virus (EBV) BFLF2 (37-39), the homologue of $P R V U L 31$, have been extensively studied; however, the precise function propers of PRVUL31 gene, as well as its codon usage bias is weakly understood.

\section{Materials and Methods}

\subsection{Virus Species and Gene Sequences}

Implication for health policy / practice / research / medical education:

These results may further our comprehending of the evolution, pathogenesis and functional studies of PRV, as well as contributing to the area of herpesvirus research or even studies with other viruses.

Copyright (c) 2013, National Institute of Genetic Engineering and Biotechnology; Published by Kowsar Corp. This is an Open Access article distributed under the terms of the Creative Commons Attribution License (http:// creativecommons.org / licenses / by / 3.0), which permits unrestricted use, distribution, and reproduction in any medium, provided the original work is properly cited. 
Cai $\mathrm{M}$ et al.

The nucleotide sequences of PRV Becker strain UL31 gene (GenBank accession no. JF797219) and the UL31-like genes of 48 reference herpesviruses were gained from the GenBank.

\subsection{Molecular Phylogenetic Tree of UL31-Like Pro- teins of the 49 Reference Herpesviruses}

To compare with those of UL31-like proteins of the 49 reference herpesviruses, then multiple sequence alignment and phylogenetic analysis (rooted tree) were carried out by employing the DNAStar (version 7.0, DNAStar, Inc.) (40).

\subsection{Codon Usage Analysis of the PRV Becker Strain UL31 Gene and other 48 Reference Herpesviruses}

For each gene, codon usage was estimated by using CAI, CHIPS and CUPS programs of EMBOSS. ENc, GC3s and RSCU were analyzed $(41,43)$. Values of $E N c$ can range from 20 (when only one codon is used per aa) to 61 (when all synonyms are used with equal frequency). Thus, ENC can be a useful measure of general codon usage bias. The lower the $E N c$, the higher the codon bias. GC3s is a useful parameter of the extent of base composition bias, and stands for the frequency of the nucleotide $\mathrm{G}+\mathrm{C}$ at the synonymous third position of codons, except for Met, Trp and the stop codons. A heat map to represent the clustering of RSCU values was generated by the CIMMiner software tool (44) with each row representing a specific codon and each column representing a different species. Clustering was accomplished based on Euclidean distance and the average linkage method. Curves were created using a logarithmic distribution curve where $\mathrm{y}=-18.564 \operatorname{Ln}(\mathrm{x})+36.503, \mathrm{y}=$ $1.8179 \operatorname{Ln}(x)+33.257$ and $y=0.4539 \operatorname{Ln}(x)-2.4428$ were used for calculating the points for ENc-GC3s, ENc-Length and GC3s-Length, respectively.

\subsection{Statistical Analysis}

The correlations between codon usage variations among the PRV UL31 gene and 48 reference herpesviruses and four indicators (CAI, ENc, GC3s and gene length) were estimated by using the SPSS 12.0 software package.

\section{Results}

4.1. Molecular Phylogenetic tree of the UL31-Like Proteins in PRV Becker Strain and the Reference Herpesviruses

A phylogenetic tree as the basis of the deduced UL31 and its UL31-like proteins in the reference herpesviruses was generated. We can see that the proteins could be preliminary separated into different subfamilies, i.e. Alpha herpesvirinae, Beta herpesvirinae and Gamma herpesvirinae
$(20,21)$. Simultaneously, it is shown that the UL31 of PRV Becker strain clusters with Bartha, Kaplan and Ea strains are initially placed in a monophyletic clade and then clustered with Bovine herpesvirus 1 (BoHV-1) and BoHV-5 of the genus Varicellovirus of subfamily alpha herpesvirus, sequently they clustered with other members of the reference species.

\subsection{Codon Usage Analysis of the UL31 Gene in PRV Becker Strain and the Reference Herpesviruses}

Codon usage in the PRV UL31 gene and its homologous genes is highly nonrandom. However, there are some diverse patterns in the codon usage bias parameters of the UL31 gene among the PRV Becker, Kaplan, Bartha and Ea strains. It can be seen in Table 1 that the CAI values of distinct herpesviruses vary from 0.602 to 0.842 , with a mean value of 0.720 and a standard deviation (SD) of 0.062 and their ENc values range from 37.345 to 59.619, with a mean value of 45.644 and SD of 9.958. Compared to other species, the ENc values of different PRV strains are much lower $(E N C<40)$, the codon usage bias in the UL31-like genes of 49 reference species, especially the PRV is therefore, slightly high. If a specific gene is exposed to $\mathrm{G}+\mathrm{C}$ compositional restriction for shaping the codon usage pattern, it will lie on a continuous curve, representing random codon usage (45). The ENc values of each UL31 -like gene in the 49 reference herpesviruses are plotted against their corresponding GC3s in Figure 1.

Here, the plot of gene length against ENC (Figure $1 \mathrm{~B}$ ) or against GC3s (Figure 1 C) shows the distribution for each gene. It seems that in the UL31-like genes of the 49 reference herpesviruses, shorter or longer genes both have a similar variance in ENc values and GC3s. It suggested that gene length may not play a role in shaping the codon usage bias of the 49 reference species. Similar results were also established in P. aeruginosa; duck plagued virus and SARS coronavirus $(5,46,47)$.

\subsection{Variation in the PRV Becker Strain UL31 Gene Codon Usage and a Composition}

While the CAI, ENc and the related measures present the overall codon bias of PRVUL31 gene. Table 2 shows the overall codon preference of the UL31 gene in the PRVBecker strain. Moreover, Cys, Asp, Glu, His, Ile, Lys, Asn, Gln and Tyr also have a high level of variety in codon usage bias, even though they only have two-fold or three-fold coding degeneracy. Altogether, although the most and the least frequencies' utilized codons of all the aa are disparate, the analyzed PRV Becker strain, UL31 gene discloses meaningful preference for one or more than one suppose codon for each aa. However, a similar bias also exists at the first position, indicating a more complicated situation exists in reality. 
Cai M et al.

Table 1. Summary Analysis of the PRV Becker Strain UL31 Gene and the UL31-Like Genes of 40 Reference Herpesviruses from Different Species

\begin{tabular}{|c|c|c|c|c|c|c|}
\hline Rank & Virus name & Strain & CAI $^{\mathrm{a}}$ & ENc $^{\mathrm{b}}$ & Coding $\mathrm{GC}^{\mathrm{C}}(\%)$ & GC3s $^{\mathrm{d}}(\%)$ \\
\hline 1 & SuHV-1 & Becker & 0.781 & 29.887 & 69.49 & 93.38 \\
\hline 2 & SuHV-1 & Bartha & 0.781 & 29.887 & 69.49 & 93.38 \\
\hline 3 & SuHV-1 & Kaplan & 0.781 & 29.887 & 69.49 & 93.38 \\
\hline 4 & SuHV-1 & Ea & 0.763 & 30.441 & 69.49 & 93.01 \\
\hline 5 & $E H V-1$ & $A b 4$ & 0.698 & 55.871 & 54.03 & 58.72 \\
\hline 6 & $E H V-4$ & NS80567 & 0.660 & 56.065 & 49.34 & 46.79 \\
\hline 7 & $E H V-9$ & P19 & 0.696 & 55.147 & 54.03 & 59.33 \\
\hline 8 & CeHV-9 & Delta & 0.602 & 47.173 & 39.01 & 27.33 \\
\hline 9 & $\mathrm{FeHV}-1$ & $C-27$ & 0.614 & 55.089 & 42.41 & 35.21 \\
\hline 10 & BoHV-1 & $\begin{array}{l}\text { Composite of } 5 \\
\text { strains }\end{array}$ & 0.733 & 38.540 & 68.97 & 81.49 \\
\hline 11 & BoHV-5 & SV507/99 & 0.787 & 31.869 & 73.60 & 93.42 \\
\hline 12 & $H H V-3$ & Dumas & 0.636 & 59.061 & 46.75 & 44.09 \\
\hline 13 & $H H V-1$ & CR38 & 0.773 & 39.023 & 65.47 & 84.36 \\
\hline 14 & $H H V-2$ & HG52 & 0.806 & 34.518 & 67.97 & 89.54 \\
\hline 15 & $\mathrm{CeHV}-1$ & E2490 & 0.802 & 31.731 & 71.08 & 93.05 \\
\hline 16 & $\mathrm{CeHV}-2$ & B264 & 0.807 & 31.340 & 72.02 & 93.77 \\
\hline 17 & CeHV-16 & X313 & 0.803 & 29.793 & 73.20 & 96.73 \\
\hline 18 & SaHV-1 & $M V 5-4$ & 0.740 & 37.991 & 67.98 & 85.41 \\
\hline 19 & GaHV-2 & $G A$ & 0.619 & 52.085 & 39.20 & 31.23 \\
\hline 20 & GaHV-3 & HPRS24 & 0.658 & 56.283 & 47.98 & 51.80 \\
\hline 21 & MeHV-1 & FC126 & 0.646 & 57.498 & 41.83 & 38.89 \\
\hline 22 & AnHV-1 & $V A C$ & 0.644 & 57.824 & 47.27 & 42.44 \\
\hline 23 & GaHV-1 & A489 & 0.662 & 58.452 & 45.50 & 44.13 \\
\hline 24 & PsHV-1 & $97-0001$ & 0.720 & 48.045 & 60.40 & 77.46 \\
\hline 25 & HGTHV & & 0.682 & 46.908 & 56.28 & 64.94 \\
\hline 26 & $H H V-5$ & U11 & 0.748 & 36.433 & 60.74 & 84.08 \\
\hline 27 & SaHV-3 & SqSHV & 0.737 & 59.619 & 46.16 & 56.12 \\
\hline 28 & $\mathrm{CeHV}-5$ & 2715 & 0.809 & 40.102 & 56.22 & 80.28 \\
\hline 29 & $M u H V-2$ & Maastricht & 0.778 & 27.345 & 65.90 & 94.72 \\
\hline 30 & $M u H V-1$ & $C$ & 0.759 & 35.975 & 62.28 & 85.03 \\
\hline 31 & $H H V-7$ & $R K$ & 0.624 & 47.309 & 32.44 & 28.46 \\
\hline 32 & $H H V-6$ & U1102 & 0.672 & 50.639 & 42.39 & 49.43 \\
\hline 33 & CavHV-2 & 21222 & 0.714 & 47.403 & 53.19 & 71.43 \\
\hline 34 & PCMV & 489 & 0.719 & 48.387 & 48.44 & 70.31 \\
\hline 35 & $M u H V-4$ & g2.4 & 0.739 & 54.592 & 50.85 & 60.75 \\
\hline 36 & AtHV-3 & 73 & 0.648 & 46.789 & 35.11 & 30.53 \\
\hline 37 & SaHV-2 & 11 & 0.666 & 41.686 & 34.22 & 30.15 \\
\hline 38 & $H H V-8$ & GK18 & 0.695 & 51.238 & 54.79 & 65.35 \\
\hline 39 & CeHV-17 & 17577 & 0.686 & 52.416 & 53.91 & 65.10 \\
\hline 40 & BoHV-4 & & 0.710 & 46.979 & 40.94 & 48.99 \\
\hline
\end{tabular}

a codon adaptation index

$\mathrm{b}$ effective number of codons

${ }^{c} \mathrm{G}+\mathrm{C}$ content in the

$\mathrm{d}_{\mathrm{G}}+\mathrm{C}$ content at the third positions of codons. All these indices were calculated by using CAI, CHIPS and CUPS programs of EMBOSS. 
Cai Met al.

Table 2. The Result of Codon Preferences in PRV Becker Strain UL31 Gene Analyzed with the CUSP Program

\begin{tabular}{|c|c|c|c|c|c|c|c|c|c|c|c|}
\hline Codon & AA & Fraction & Frequency & Number & RSCU & Codon & AA & Fraction & Frequency & Number & RSCU \\
\hline $\mathbf{G C A}^{\mathrm{a}}$ & A(Ala) & 0.029 & 3.676 & 1 & 0.118 & CCA & P(Pro) & 0.000 & 0.000 & 0 & 0.000 \\
\hline $\mathbf{G C ~ C}^{\mathrm{b}}$ & A & 0.529 & 66.176 & 18 & 2.118 & $\mathrm{CCC}^{\mathrm{b}}$ & $P$ & 0.688 & 40.441 & 11 & 2.750 \\
\hline GCG & A & 0.441 & 55.147 & 15 & 1.765 & CCG & $P$ & 0.250 & 14.706 & 4 & 1.000 \\
\hline GCT & A & 0.000 & 0.000 & 0 & 0.000 & $\mathrm{CCT}^{\mathrm{a}}$ & $\mathrm{P}$ & 0.062 & 3.676 & 1 & 0.250 \\
\hline TGC $^{\mathrm{b}}$ & C(Cys) & 1.000 & 22.059 & 6 & 2.000 & CAA & $\mathrm{Q}(\mathrm{Gln})$ & 0.000 & 0.000 & 0 & 0.000 \\
\hline TGT & $\mathrm{C}$ & 0.000 & 0.000 & 0 & 0.000 & $\mathrm{CAG}^{\mathrm{b}}$ & Q & 1.000 & 22.059 & 6 & 2.000 \\
\hline GAC $^{b}$ & $\mathrm{D}$ (Asp) & 0.944 & 62.500 & 17 & 1.889 & $\mathrm{AGA}^{\mathrm{a}}$ & $\mathrm{R}(\operatorname{Arg})$ & 0.069 & 7.353 & 2 & 0.414 \\
\hline GAT $^{\mathrm{a}}$ & $\mathrm{D}$ & 0.056 & 3.676 & 1 & 0.111 & AGG & $\mathrm{R}$ & 0.000 & 0.000 & 0 & 0.000 \\
\hline $\mathbf{G A A}^{\mathrm{a}}$ & $\mathrm{E}(\mathrm{Glu})$ & 0.077 & 3.676 & 1 & 0.154 & $\mathrm{CGA}^{\mathrm{a}}$ & $\mathrm{R}$ & 0.069 & 7.353 & 2 & 0.414 \\
\hline GAG $^{\mathrm{b}}$ & E & 0.923 & 44.118 & 12 & 1.846 & $\mathrm{CGC}^{\mathrm{b}}$ & $\mathrm{R}$ & 0.621 & 66.176 & 18 & 3.724 \\
\hline TTC $^{b}$ & F(Phe) & 0.615 & 29.412 & 8 & 1.231 & CGG & $\mathrm{R}$ & 0.241 & 25.735 & 7 & 1.448 \\
\hline TTT $^{a}$ & $\mathrm{~F}$ & 0.385 & 18.382 & 5 & 0.769 & CGT & $\mathrm{R}$ & 0.000 & 0.000 & 0 & 0.000 \\
\hline $\mathbf{G G A}^{\mathrm{a}}$ & G(Gly) & 0.062 & 3.676 & 1 & 0.250 & $\mathrm{AGC}^{\mathrm{a}}$ & S(Ser) & 0.357 & 18.382 & 5 & 2.143 \\
\hline $\mathbf{G G C}^{\mathrm{b}}$ & G & 0.625 & 36.765 & 10 & 2.500 & AGT & $S$ & 0.000 & 0.000 & 0 & 0.000 \\
\hline GGG & G & 0.312 & 18.382 & 5 & 1.250 & TCA & $S$ & 0.000 & 0.000 & 0 & 0.000 \\
\hline GGT & G & 0.000 & 0.000 & 0 & 0.000 & TCC & S & 0.000 & 0.000 & 0 & 0.000 \\
\hline $\mathrm{CAC}^{\mathrm{b}}$ & H(His) & 1.000 & 22.059 & 6 & 2.000 & $\mathrm{TCG}^{\mathrm{b}}$ & S & 0.643 & 33.088 & 9 & 3.857 \\
\hline CAT & $\mathrm{H}$ & 0.000 & 0.000 & 0 & 0.000 & TCT & $S$ & 0.000 & 0.000 & 0 & 0.000 \\
\hline ATA & I(Ile) & 0.000 & 0.000 & 0 & 0.000 & ACA & $\mathrm{T}(\mathrm{Thr})$ & 0.000 & 0.000 & 0 & 0.000 \\
\hline $\mathrm{ATC}^{\mathrm{b}}$ & I & 0.800 & 14.706 & 4 & 2.400 & $\mathrm{ACC}^{\mathrm{a}}$ & $\mathrm{T}$ & 0.375 & 11.029 & 3 & 1.500 \\
\hline $\mathbf{A T T}^{\mathrm{a}}$ & I & 0.200 & 3.676 & 1 & 0.600 & $\mathrm{ACG}^{\mathrm{b}}$ & $\mathrm{T}$ & 0.625 & 18.382 & 5 & 2.500 \\
\hline $\mathbf{A A A}^{\mathrm{a}}$ & K(Lys) & 0.125 & 3.676 & 1 & 0.250 & ACT & $\mathrm{T}$ & 0.000 & 0.000 & 0 & 0.000 \\
\hline $\mathrm{AAG}^{\mathrm{b}}$ & $\mathrm{K}$ & 0.875 & 25.735 & 7 & 1.750 & GTA & $\mathrm{V}(\mathrm{Val})$ & 0.000 & 0.000 & 0 & 0.000 \\
\hline CTA & L(Leu) & 0.000 & 0.000 & 0 & 0.000 & GTC $^{a}$ & V & 0.083 & 7.353 & 2 & 0.333 \\
\hline $\mathrm{CTC}^{\mathrm{b}}$ & $\mathrm{L}$ & 0.484 & 55.147 & 15 & 2.903 & GTG $^{b}$ & V & 0.917 & 80.882 & 22 & 3.667 \\
\hline CTG & $\mathrm{L}$ & 0.419 & 47.794 & 13 & 2.516 & GTT & V & 0.000 & 0.000 & 0 & 0.000 \\
\hline CTT & $\mathrm{L}$ & 0.000 & 0.000 & 0 & 0.000 & TGG & $\mathrm{W}(\operatorname{Trp})$ & 1.000 & 3.676 & 1 & 1.000 \\
\hline TTA & $\mathrm{L}$ & 0.000 & 0.000 & 0 & 0.000 & $\mathrm{TAC}^{\mathrm{b}}$ & $\mathrm{Y}(\mathrm{Tyr})$ & 0.929 & 47.794 & 13 & 1.857 \\
\hline TTG $^{a}$ & $\mathrm{~L}$ & 0.097 & 11.029 & 3 & 0.581 & $\mathrm{TAT}^{\mathrm{a}}$ & Y & 0.071 & 3.676 & 1 & 0.143 \\
\hline ATG & $\mathrm{M}(\mathrm{Met})$ & 1.000 & 22.059 & 6 & 1.000 & TAA & * & 0.000 & 0.000 & 0 & 0.000 \\
\hline $\mathrm{AAC}^{\mathrm{b}}$ & $\mathrm{N}($ Asn $)$ & 1.000 & 11.029 & 3 & 2.000 & TAG & * & 0.000 & 0.000 & 0 & 0.000 \\
\hline AAT & $\mathrm{N}$ & 0.000 & 0.000 & 0 & 0.000 & $\mathrm{TGA}^{\mathrm{b}}$ & ${ }^{*}$ & 1.000 & 3.676 & 1 & 3.000 \\
\hline
\end{tabular}

a codons appear during the lower frequency coding of the amino acid.

$\mathrm{b}$ codons indicate the highest frequency in coding the amino acid. Triplets in bold face indicate the lowest frequency (frequency is zero) in coding the amino acid.

Fract refers to the proportion of all synonymous codons encoding the same amino acid. The frequency of each codon that appears in the coding sequence of the individual gene is $1 / 1000$.

\subsection{Phylogenetic Persistence in Codon Usage Bias of the PRV Becker Strain UL31 Gene}

To provide a visual representation of the variation in codon bias (48-50), we carried out a cluster analysis (Fig- ure 2) of the codon usage pattern on the basis of the PRV Becker strain UL31 gene and its 48 reference herpesviruses in accord with the RSCU values. From the figure, we can see that PRV Becker, Kaplan, Barthaand Ea strains appear different from other herpesviruses. They, firstly, cluster together and from a segregated branch, then they cluster with BoHV-1 and BoHV-5 of the genus Varicellovirus of subfamily alphaherpesvirus and Cercopithecine herpesvirus 2 (CeHV-2) of the genus Simplexvirus of a subfamily alphaherpesvirus, subsequently they cluster with other mem- 
bers of the reference species. This consequence wholly indicates the internal relations of the codon usage pattern between $P R V$ and other herpesviruses, particularly the alphaherpesviruses, suggesting that the codon usage pattern of $P R V$ has distinctions with other members of the reference species, the more distant the genetic relationship, the bigger the expected variation in the codon usage bias, and vice versa. Consequently, we can conclude that the codon usage pattern of $P R V$ is fairly close to that of the members of genus Varicellovirus of alpha herpesvirus.

\subsection{Comparison of the UL31 Gene Codon Usage in} PRV Becker Strain with those of E. coli, Yeast and Human

Generally, the codon usage bias in a gene remains conserved, to a certain extent, across species. Here, the codon usage of PRV Becker strain UL31 gene was compared with those of E. coli, yeast, and human to see which would be the most appropriate host for optimal expression. From Table 2 we can see that there are 33 codons showing a $P R V$-to-yeast ratio higher than 2 or lower than 0.50 , and 24 codons showing a PRV-to-E. coli ratio higher than 2 or lower than 0.50 , but 22 codons showing a $P R V$-to-human ratio higher than 2 or lower than 0.50 , indicating that large diversities in the codon preferences exist for all three hosts. Although there were slightly fewer differences in codon usages between $P R V$ and human, the difference is unlikely to be statistically significant, and experimental studies would be necessary to assess the most suitable expression system for this virus.

\section{Discussion}

In this study, the data of synonymous codon usage bias exhibited certain different distinctions existed for each herpesvirus from different species, and the result exposed that: a) PRV Becker strain UL31 gene and its 48 reference herpesviruses adopt comparatively similar codon usage patterns; and b) the PRVBecker strain UL31 gene opts to employ the codons with $C$ and $G$ at the third codon position. Furthermore, the biased tendency towards $C$ and $G$ is consistent with the high $\mathrm{C}+\mathrm{G}$ content in PRV Becker strain UL31 gene. Since the UL31 gene in the PRV Becker strain is a CG-rich gene, it is rational that $C$ and / or G ending codons are prevalent in the gene. In order to show the codon usage variation.

Table 1 shows that the UL31 genes in alpha herpesvirus member of PRV, BoHV-1, BoHV-5, Human herpesvirus 1 (HHV1), HHV-2, CeHV-1, CeHV-2, CeHV-16 and Saimiriine herpesvirus 1 (SaHV-1), etc. whose natural host is mammalian, have a stronger correlation than other UL31 genes of the reference alpha herpesviruses with avian host, such as GaHV-1, GaHV-2, GaHV-3, Meleagrid herpesvirus 1 (MeHV-1) and Anatid herpesvirus 1 (AnHV-1). It is critical to clarify the fundamental mechanisms of codon usage pattern to perceive the evolution of the species $(51,52)$. From the phylogenetic tree (Figure 3) and cluster analysis results (Figure 1) we can see that $P R V$ is evolutionarily closer with $B o H V-1$ and BoHV-5 than GaHV-1 and PsHV-1, etc. Simultaneously, its codon usage pattern is also closer with BoHV-1 and $B o H V-5$ than other members of the reference species. Accordingly, we can draw a conclusion that species has a certain effect to the preference of codon usage, but is less substantial than the influence of gene function, and the codon usage bias of PRVUL31 gene has a very close connection with its gene function.
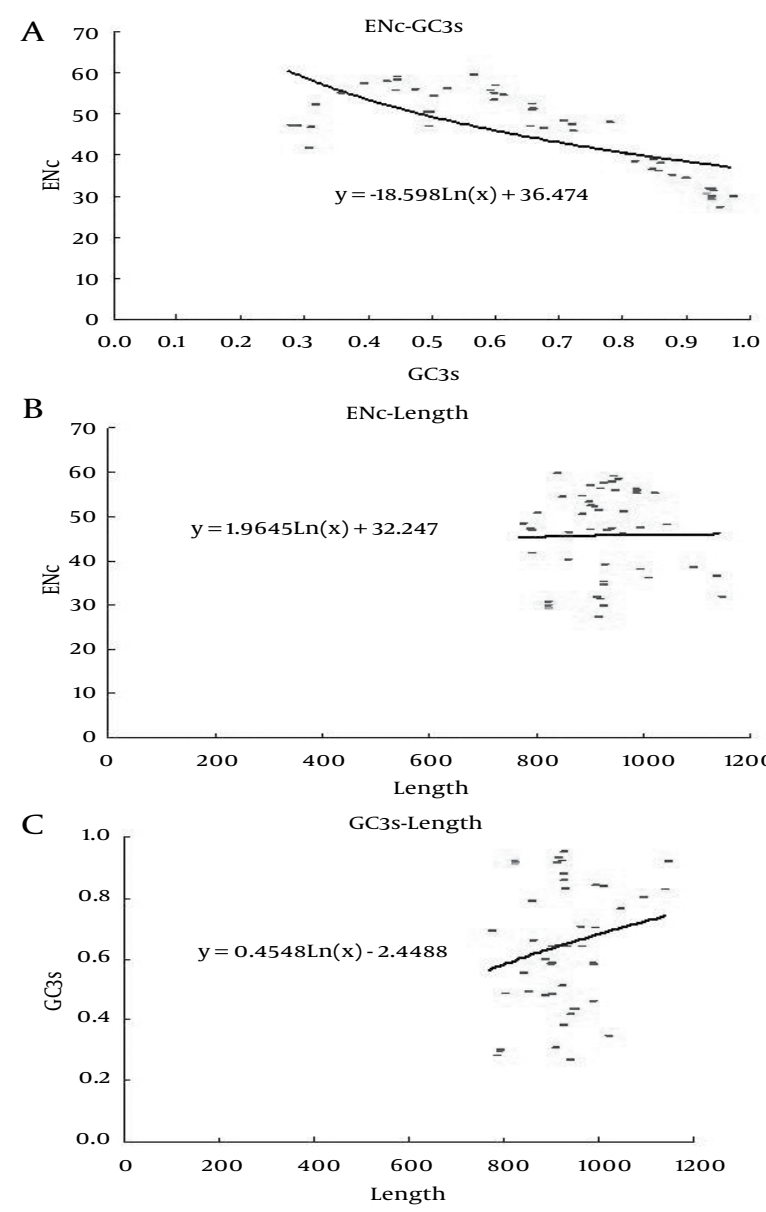

Figure 1. Relationship between ENc, GC3s and gene length of the PRV Becker strain UL31 gene and the UL31-like genes of 48 reference herpesviruses. (A) Plot of ENc versus GC3s for the PRV Becker strain UL31 gene and the UL31-like genes of 48 reference herpesviruses. ENc denotes the effective number of codons of each gene, and GC3s denotes the G + $\mathrm{C}$ content at the third synonymous codon position of each gene. The solid curve shows the expected position of genes whose codon usage is only determined by the variation in GC3s. (B) Plot of ENc versus gene length for the PRV Becker strain UL31 gene and the UL31-like genes of 48 reference herpesviruses. (C) Plot of GC3s versus gene length for the PRV Becker strain UL31 gene and the UL31-like genes of 48 reference herpesviruses. 
Cai M et al.

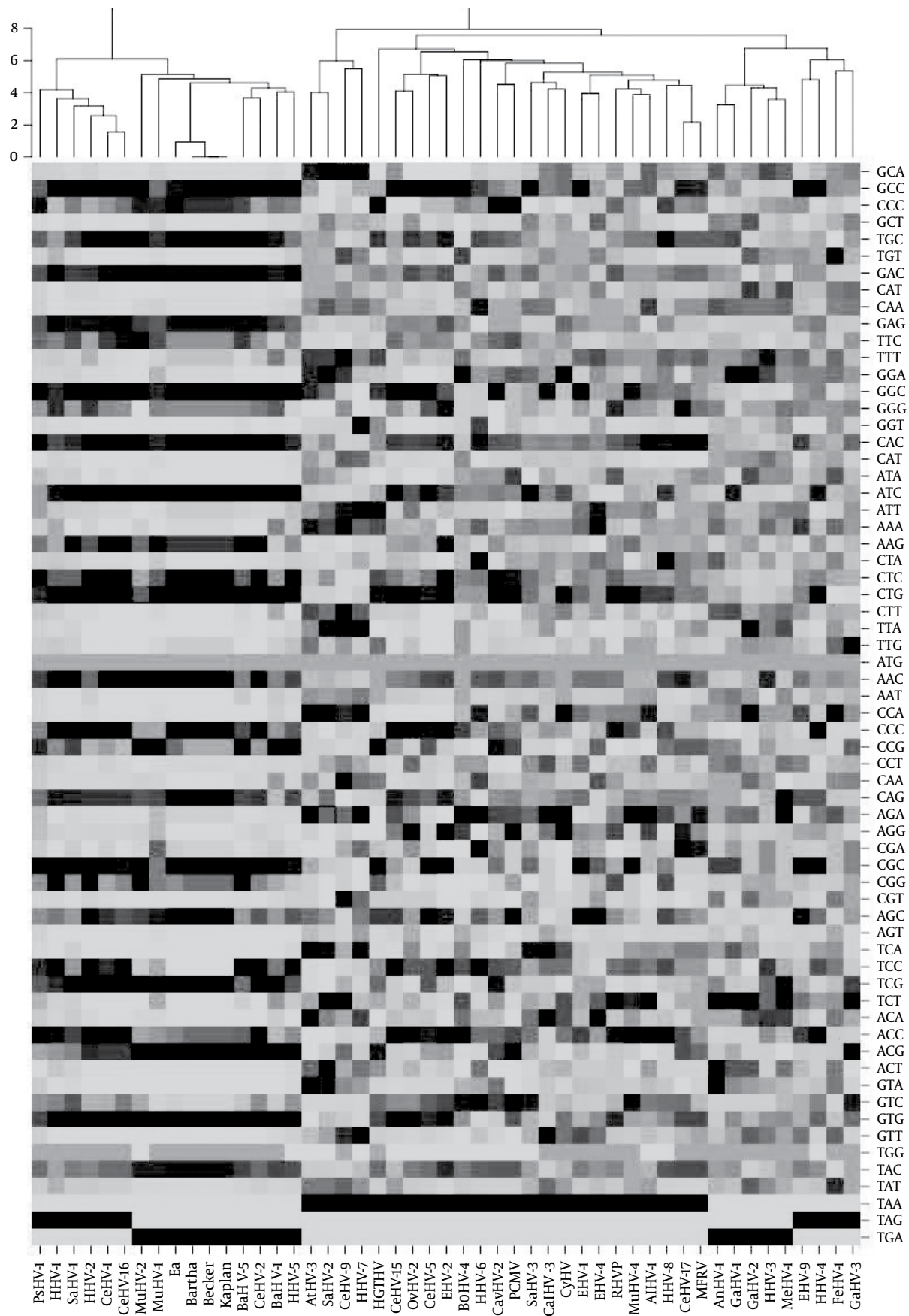

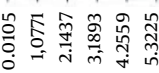

Figure 2. Heat Map of RSCU Values for the 49 Reference Herpesvirus Species (clustered by the RSCU values). Each row represents a various codon. Different species are represented in each column. Cluster is shown to the top based on euclidean distance and average method 


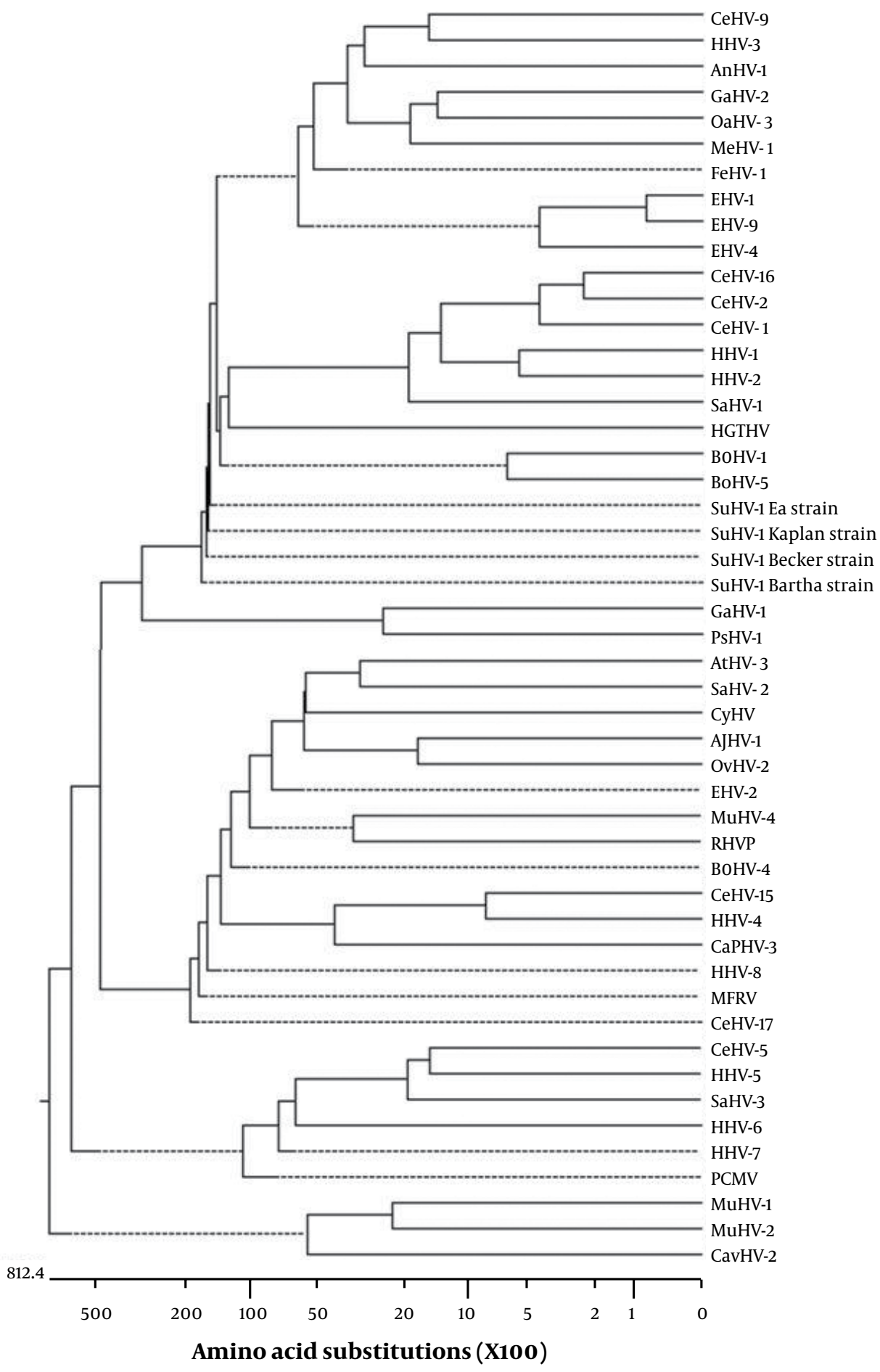

Figure 3. Evolutionary Relationship of the PRV Becker Btrain UL31 Protein with the UL31-like Proteins of 48 Reference Herpesviruses from Different species. Phylogenetic tree of these proteins was generated by using the MEGALIGN (DNAStar) program with Clustal V multiple alignment software packages and sequence distance indicated by the scale was calculated using the PAM250 matrix in LASERGENE. 
Bioinformatic's analysis reveals that PRV UL31 protein is a member of PHA03328 superfamily (data not shown), which encodes nuclear egress lamina protein UL31 and is conserved throughout the herpesvirus. Although the biological characteristics of most of the herpesviral UL31 homologues are ill understood at the present time, a common property is the interaction of UL31 and UL34, and their co-localization at the nuclear or nuclear rim happened at different herpesvirus subfamilies, such as alpha herpesvirus HSV-1 (32) and HSV-2 (53), beta herpesvirus murine cytomegalovirus (MCMV) (54), and gammaherpesvirus EBV (38) and Kaposi's sarcoma-associated herpesvirus (KSHV) (55). Another interesting feature is their significance for primary envelopment and nuclear egress in all herpesvirus subfamily $(32,35,39,56)$. Therefore, because of the crucial roles acted by the counterpart of PRV UL31 in $H S V, M C M V, E B V$ and $K S H V$ in the course of infection, it indicates that PRV UL31 may also play a similar role in the process of infection according to their phylogenetic conservation. However, it is not yet known what real biological roles of $U L 31$ have in the PRV life cycle, and the investigation of these aspects must therefore await further clarification of its functions in viral replication and the interactions between $P R V$ and host.

Among the codon usage bias fashions in E. coli, yeast and human, no clear definition of the most appropriate host could be made. Although the codon usages between $P R V$ and human were slightly better matched compared to the other hosts, they were not significantly different. Nevertheless, in a recent study, we successfully expressed the PRV UL31 protein in the human embryonic kidney 293T expression system (unpublished data).

Taken together, analysis of codon usage pattern of PRV UL31 gene and a comparison of codon preference between PRV UL31 gene and other species can offer a foundation for understanding the relevant mechanism of biased usage of synonymous codons.

\section{Acknowledgements}

There is no acknowledgment.

\section{Authors' Contributions}

MSC and MLL contributed equally to this study, both of them equally carried out most of the experiments and wrote the manuscript. MSC and MLL have critically revised the manuscript and the experimental design. JYZ, JHC, BYW and ZL helped in experiments. All the authors read and approved the final manuscript.

\section{Funding / Support}

This work was supported by grants from the Natural Science Foundation of Guangdong Province (S2013040016596); Science and Technology New Star in Zhu Jiang, Guangzhou City (2013J2200018); National
Natural Science Foundation of China (31200120); Medical Scientific Research Foundation of Guangdong Province, China (B2012165); Foundation for Distinguished Young Talents in Higher Education of Guangdong, China; First Batch of Youth Learning Backbone Teacher in Guangzhou Medical University; and Students' extracurricular scientific and technological activities in Guangzhou Medical University (2012A039 and 2012C007).

\section{Financial Disclosure}

The authors declare that they have no competing interests.

\section{References}

1. Bernardi G, Bernardi G. Compositional constraints and genome evolution. J Mol Evo. 1986;24(1-2):1-11.

2. Blaisdell BE. Choice of base at silent codon site 3 is not selectively neutral in eucaryotic structural genes: It maintains excess short runs of weak and strong hydrogen bonding bases. J Mol Evo. 1983;19(3-4):226-236.

3. Blake RD, Hinds PW. Analysis of the codon bias in E. coli sequences. J Biomol Struct Dyn. 1984;2(3):593-606.

4. Boelaert F, Deluyker H, Maes D, Godfroid J, Raskin A, Varewijck H, et al. Prevalence of herds with young sows seropositive to pseudorabies (Aujeszky's disease) in northern Belgium. Prev Vete Med. 1999;41(4):239-255.

5. Burland TG. DNASTAR's Lasergene sequence analysis software. Methods Mol Biol. 2000;132:71-91.

6. Cai MS, Cheng AC, Wang MS, Zhao LC, Zhu DK, Luo QH, et al. Characterization of synonymous codon usage bias in the duck plague virus UL35 gene. Intervirology. 2009;52(5):266-78.

7. Chang YE, Roizman B. The product of the UL31 gene of herpes simplex virus 1 is a nuclear phosphoprotein which partitions with the nuclear matrix. J Virol. 1993;67(11):6348-56.

8. Comeron JM, Aguade M. An evaluation of measures of synonymous codon usage bias. J Mol Evol. 1998;47(3):268-74.

9. Dass JF, Sudandiradoss C. Insight into pattern of codon biasness and nucleotide base usage in serotonin receptor gene family from different mammalian species. Gene. 2012;503(1):92-100.

10. D'Onofrio G, Ghosh TC, Bernardi G. The base composition of the genes is correlated with the secondary structures of the encoded proteins. Gene. 2002;300(1-2):179-187.

11. Duret L. Evolution of synonymous codon usage in metazoans. Curr Opin Gen \& Dev. 2002;12(6):640-649.

12. Fu M. Codon usage bias in herpesvirus. Arch Virol. 2010;155(3):391-

13. Fuchs W, Klupp BG, Granzow H, Osterrieder N, Mettenleiter TC. The interacting UL31 and UL34 gene products of pseudorabies virus are involved in egress from the host-cell nucleus and represent components of primary enveloped but not mature virions. J Virol. 2002;76(1):364-78.

14. Gonnella R, Farina A, Santarelli R, Raffa S, Feederle R, Bei R, et al. Characterization and intracellular localization of the EpsteinBarr virus protein BFLF2: interactions with BFRF1 and with the nuclear lamina. J Virol. 2005;79(6):3713-27.

15. Gouy M, Gautier C. Codon usage in bacteria: correlation with gene expressivity. Nucleic Acids Res. 1982;10(22):7055-74.

16. Granato M, Feederle R, Farina A, Gonnella R, Santarelli R, Hub B et al. Deletion of Epstein-Barr virus BFLF2 leads to impaired viral DNA packaging and primary egress as well as to the production of defective viral particles. JVirol. 2008;82(8):4042-51.

17. Grantham R, Gautier C, Gouy M, Jacobzone M, Mercier R. Codon catalog usage is a genome strategy modulated for gene expressivity. Nucleic Acids Res. 1981;9(1):r43-74.

18. Grosjean H, Fiers W. Preferential codon usage in prokaryotic genes: the optimal codon-anticodon interaction energy and 
the selective codon usage in efficiently expressed genes. Gene. 1982;18(3):199-209.

19. Gu W, Zhou T, Ma J, Sun X, Lu Z. Analysis of synonymous codon usage in SARS Coronavirus and other viruses in the Nidovirales. Virus Res. 2004;101(2):155-61.

20. Gupta SK, Ghosh TC. Gene expressivity is the main factor in dictating the codon usage variation among the genes in Pseudomonas aeruginosa. Gene. 2001;273(1):63-70.

21. Hooper SD, Berg OG. Gradients in nucleotide and codon usage along Escherichia coli genes. Nucleic Acids Res. 2000;28(18):3517-23.

22. Ikemura T. Codon usage and tRNA content in unicellular and multicellular organisms. Mol Biol Evol. 1985;2(1):13-34.

23. Jiang Peng, Sun Xiao, Lu Zuhong. Analysis of Synonymous Codon Usage in Aeropyrum pernix K1 and Other Crenarchaeota Microorganisms. J Gene Genom. 2007;34(3):275-284.

24. Kato A, Yamamoto M, Ohno T, Tanaka M, Sata T, Nishiyama Y, et al. Herpes simplex virus 1-encoded protein kinase UL13 phosphorylates viral Us3 protein kinase and regulates nuclear localization of viral envelopment factors UL34 and UL31.J Virol. 2006;80(3):1476-86.

25. Koppers-Lalic D, Reits EA, Ressing ME, Lipinska AD, Abele R, Koch J, et al. Varicelloviruses avoid T cell recognition by UL49.5-mediated inactivation of the transporter associated with antigen processing. Proc Natl Acad Sci U S A. 2005;102(14):5144-9.

26. Lake CM, Hutt-Fletcher LM. The Epstein-Barr virus BFRF1 and BFLF2 proteins interact and coexpression alters their cellular localization. Virology. 2004;320(1):99-106.

27. Li M, Wang S, Cai M, Guo H, Zheng C. Characterization of molecular determinants for nucleocytoplasmic shuttling of PRV UL54. Virology. 2011;417(2):385-93.

28. Li M, Wang S, Cai M, Zheng C. Identification of nuclear and nucleolar localization signals of pseudorabies virus (PRV) early protein UL54 reveals that its nuclear targeting is required for efficient production of PRV.J Virol. 2011;85(19):10239-51.

29. Li M, Zhao Z, Chen J, Wang B, Li Z, Li J, et al. Characterization of synonymous codon usage bias in the pseudorabies virus US gene. Virol Sin. 2012;27(5):303-15.

30. Liang L, Baines JD. Identification of an essential domain in the herpes simplex virus 1 UL34 protein that is necessary and sufficient to interact with UL31 protein. JVirol. 2005;79(6):3797-806.

31. Liu Q, Dou S, Ji Z, Xue Q. Synonymous codon usage and gene function are strongly related in Oryza sativa. Biosystems. 2005;80(2):123-31.

32. Lobry JR, Gautier C. Hydrophobicity, expressivity and aromaticity are the major trends of amino-acid usage in 999 Escherichia col chromosome-encoded genes. Nucleic Acids Res. 1994;22(15):3174-80.

33. Lotzerich M, Ruzsics Z, Koszinowski UH. Functional domains of murine cytomegalovirus nuclear egress protein M53 / p38. JVirol. 2006;80(1):73-84.

34. Maruyama T, Gojobori T, Aota S, Ikemura T. Codon usage tabulated from the GenBank genetic sequence data. Nucleic Acids Res. 1986;14 Suppl:r151-97.

35. Miller MS, Furlong WE, Pennell L, Geadah M, Hertel L. RASCAL is a new human cytomegalovirus-encoded protein that localizes to the nuclear lamina and in cytoplasmic vesicles at late times postinfection. J Virol. 2010;84(13):6483-96.

36. Mou F, Wills E, Baines JD. Phosphorylation of the $\mathrm{U}(\mathrm{L}) 31$ protein of herpes simplex virus 1 by the U(S)3-encoded kinase regulates localization of the nuclear envelopment complex and egress of nucleocapsids. JVirol. 2009;83(10):5181-91.

37. Müller T, Bätza HJ, Schlüter H, Conraths FJ, Mettenleiter TC. Eradi- cation of Aujeszky's Disease in Germany. Journal of Veterinary Medicine, Series B. 2003;50(5):207-213.

38. Muller T, Hahn EC, Tottewitz F, Kramer M, Klupp BG, Mettenleiter TC, et al. Pseudorabies virus in wild swine: a global perspective. Arch Virol. 2011:156(10):1691-705.

39. Najafabadi HS, Goodarzi H, Salavati R. Universal function-specificity of codon usage. Nucleic Acids Res. 2009;37(21):7014-23.

40. Yang K, Baines JD. Selection of HSV capsids for envelopment in volves interaction between capsid surface components pUL31, pUL17, and pUL25. Proc Natl Acad Sci US A. 2011;108(34):14276-81.

41. Novembre J A. Accounting for Background Nucleotide Composition When Measuring Codon Usage Bias. Mol Biol Evol. 2002;19(8):1390-1394.

42. Ye GJ, Roizman B. The essential protein encoded by the UL31 gene of herpes simplex virus 1 depends for its stability on the presence of UL34 protein. Proc Natl Acad Sci U S A. 2000;97(20):11002-7.

43. Ono E, Amagai K, Yoshino S, Taharaguchi S, Inobe M, Uede. Resistance to pseudorabies virus infection in transformed cell lines expressing a soluble form of porcine herpesvirus entry mediator C. JGeneral Virol. 2004;85(1):173-178.

44. Pomeranz LE, Reynolds AE, Hengartner CJ. Molecular biology of pseudorabies virus: impact on neurovirology and veterinary medicine. Microbiol Mol Biol Rev. 2005;69(3):462-500.

45. Reynolds AE, Ryckman BJ, Baines JD, Zhou Y, Liang L, Roller RJ $\mathrm{U}(\mathrm{L}) 31$ and $\mathrm{U}(\mathrm{L}) 34$ proteins of herpes simplex virus type 1 form a complex that accumulates at the nuclear rim and is required for envelopment of nucleocapsids. JVirol. 2001;75(18):8803-17.

46. Roberts KL, Baines JD. UL31 of herpes simplex virus 1 is necessary for optimal NF-kappaB activation and expression of viral gene products. J Virol. 2011;85(10):4947-53.

47. Roychoudhury S, Mukherjee D. A detailed comparative analysis on the overall codon usage pattern in herpesviruses. Virus Res. 2010;148(1-2):31-43.

48. Santarelli R, Farina A, Granato M, Gonnella R, Raffa S, Leone L, et al. Identification and characterization of the product encoded by ORF69 of Kaposi's sarcoma-associated herpesvirus. J Virol. 2008;82(9):4562-72.

49. Sharp PM, Averof M, Lloyd AT, Matassi G, Peden JF. DNA sequence evolution: the sounds of silence. Philos Trans R Soc Lond B Biol Sci. 1995;349(1329):241-7.

50. Simpson-Holley M, Baines J, Roller R, Knipe DM. Herpes simplex virus $1 \mathrm{U}(\mathrm{L}) 31$ and $\mathrm{U}(\mathrm{L}) 34$ gene products promote the late maturation of viral replication compartments to the nuclear periphery. JVirol. 2004;78(11):5591-600.

51. Wada A, Suyama A. Local stability of DNA and RNA secondary structure and its relation to biological functions. Prog Biophys Mol Biol. 1986;47(2):113-157.

52. Wain-Hobson S, Nussinov R, Brown RJ, Sussman JL. Preferential codon usage in genes. Gene. 1981;13(4):355-364.

53. Weinstein JN, Myers TG, O'Connor PM, Friend SH, Fornace AJ, Kohn KW, et al. An Information-Intensive Approach to the Molecular Pharmacology of Cancer. Science. 1997;275(5298):343-349.

54. White AK, Ciacci-Zanella J, Galeota J, Ele S, Osorio FA. Comparison of the abilities of serologic tests to detect pseudorabies-infected pigs during the latent phase of infection. Am JVet Res.1996;57(5):608-11.

55. Wright $\mathrm{F}$. The 'effective number of codons' used in a gene. Gene 1990;87(1):23-29.

56. Yamauchi Y, Shiba C, Goshima F, Nawa A, Murata T, Nishiyama Y Herpes simplex virus type 2 UL34 protein requires UL31 protein for its relocation to the internal nuclear membrane in transfected cells.J Gen Virol. 2001;82(Pt 6):1423-8. 